\title{
AS CIÊNCIAS SOCIAIS E O DESAFIO DA ANTROPOLOGIA NA PRÁTICA DOCENTE NA EDUCAÇÃO BÁSICA
}

\author{
LAS CIENCIAS SOCIALES Y EL DESAFÍO DE LA ANTROPOLOGÍA EN LA \\ PRÁCTICA DOCENTE EN EDUCACIÓN BÁSICA
}

\section{THE SOCIAL SCIENCES AND THE CHALLENGE OF ANTHROPOLOGY IN THE TEACHING PRACTICE IN BASIC EDUCATION}

Eliane Anselmo da SILVA ${ }^{1}$ Raoni Borges BARBOSA ${ }^{2}$ Lidiane Alves da CUNHA ${ }^{3}$

RESUMO: As Ciências Sociais demarcam sua importância na construção da identidade plural e democrática da sociedade moderna, cujos princípios civilizadores foram historicamente representados no processo de elaboração do discurso sociológico, antropológico e politológico do progresso civilizacional. No Brasil, nos últimos anos, começam a se pautar debates mais aprofundados em torno do ensino das Ciências Sociais na Educação Básica. A partir da obrigatoriedade do ensino da Sociologia, compreendida enquanto espaço formativo das Ciências Sociais no Ensino Médio, a sociedade brasileira passou a refletir sobre o lugar da Antropologia na escola. Nessa perspectiva se originam nossas pesquisas, no intuito de compreender o processo de ensino/aprendizagem da Antropologia no âmbito da Educação Básica. A proposta deste artigo é refletir sobre as contribuições do saber antropológico e das Ciências Sociais no contexto escolar, pensando seus desafios e contribuições na prática docente e na construção da reflexividade crítica sobre a sociedade e a cultura.

PALAVRAS-CHAVE: Antropologia. Ciências sociais. Educação básica. Ensino. Prática docente.

RESUMEN: Las Ciencias Sociales demarcan su importancia en la construcción de la identidad plural y democrática de la sociedad moderna, cuyos principios civilizadores han sido históricamente representados en el proceso de elaboración del discurso sociológico, antropológico y politológico del progreso civilizacional. En Brasil, en los últimos años, se comenzaron a orientar debates más profundos sobre la enseñanza de las Ciencias Sociales en

\footnotetext{
${ }^{1}$ Universidade do Estado do Rio Grande do Norte (UERN), Mossoró - RN - Brasil. Professora Adjunta IV vinculada ao Departamento de Ciências Sociais e Políticas e Vice Coordenadora do Programa de Pós-Graduação em Ensino. Doutorado em Antropologia (UFPE). ORCID: https://orcid.org/0000-0002-6624-8493. E-mail: elianeanselno@uern.br

${ }^{2}$ Universidade do Estado do Rio Grande do Norte (UERN), Mossoró - RN - Brasil. Professor Visitante vinculado ao Departamento de Ciências Sociais e Políticas e ao Programa de Pós-Graduação em Ciências Sociais e Humanas. Doutorado em Antropologia (UFPE). ORCID: https://orcid.org/0000-0002-2437-3149. E-mail: raoniborgesb@gmail.com

${ }^{3}$ Universidade do Estado do Rio Grande do Norte (UERN), Mossoró - RN - Brasil. Professora Adjunta IV vinculada ao Departamento de Ciências Sociais e Políticas e Coordenadora do Programa de Iniciação à Docência em Ciências Sociais - PIBID. Doutorado em Ciências Sociais (UFRN). ORCID: https://orcid.org/0000-00032161-9446. E-mail: lidianecunha@uern.br
} 
la Educación Básica. A partir de la obligatoriedad de la enseñanza de la Sociología, entendida como un espacio formativo de las Ciencias Sociales en el Bachillerato, la sociedad brasileña comenzó a reflexionar sobre el lugar de la Antropología en la escuela. Desde esta perspectiva se origina nuestra investigación, con el fin de comprender el proceso de enseñanza / aprendizaje de la Antropología en el ámbito de la Educación Básica. El propósito de este artículo es reflexionar sobre los aportes del conocimiento antropológico y las Ciencias Sociales en el contexto escolar, reflexionando sobre sus retos y aportes en la práctica docente y en la construcción de la reflexividad crítica sobre la sociedad y la cultura.

PALABRAS ClaVE: Antropología. Ciencias sociales. Educación básica. Enseñanza. Práctica docente.

ABSTRACT: The Social Sciences demarcate their importance in the construction of the plural and democratic identity of modern society, whose civilizing principles have been historically represented in the process of elaborating the sociological, anthropological and politological discourse of civilizational progress. In Brazil, in recent years, more in-depth debates about the teaching of Social Sciences in Basic Education began to be guided. Since the mandatory teaching of Sociology, understood as a formative space in Social Sciences in High School, Brazilian society began to reflect on the place of Anthropology in school. In this perspective our research originates, in order to understand the teaching / learning process of Anthropology in the scope of Basic Education. Thus, the purpose of this article is to reflect on the contributions of anthropological knowledge and Social Sciences in the school context, thinking about their challenges and contributions in the teaching practice and in the construction of critical reflexivity about society and culture.

KEYWORDS: Anthropology. Social sciences. Basic education. Teaching. Teaching practice.

\section{Introdução}

A escola constitui um dos diversos espaços de formação para o mundo social que a Antropologia tem alcançado nos últimos anos. Os debates têm se intensificado no país em torno do seu ensino na educação básica, a partir da disciplina de Sociologia, compreendida enquanto lócus formativo das ciências sociais. Mas a própria Sociologia, que tem seu ensino obrigatório no Ensino Médio com a implementação da Lei 11.684, em junho de 2008, após quase 40 anos, quando havia sido banida do currículo em 1971 e substituída por Educação Moral e Cívica, novamente tem seu espaço fragilizado, pela nova reforma do Ensino Médio (BRASIL, 2008). A Lei da Reforma do Ensino Médio, de $\mathrm{n}^{\circ} 13.415 / 2017$, visa a implementação de itinerários formativos no Ensino Médio, reduzindo os conhecimentos presentes nessa etapa escolar, visto que diminuirá o acesso de alunos da Rede Pública a conteúdos fundamentais para sua formação integral (BRASIL, 2017a). A Sociologia é um desses conhecimentos, e a retirada desta disciplina do currículo escolar terá como 
consequência o não desenvolvimento da percepção crítica acerca da sociedade, das relações sociais, das estruturas simbólicas da cultura, do jogo institucional e político cotidiano, dos processos de formação da pessoa em sociabilidades urbanas plurais, entre outros.

Nosso intuito, aqui, não é analisar os impactos gerados pela Reforma do Ensino Médio a partir da abordagem analítica do ensino de Sociologia, mas apontar a importância dessa disciplina, mostrando que, desde sua obrigatoriedade, em 2008, a mesma vem contribuindo para a construção de uma escola crítica, reflexiva e mais democrática, tendo como foco os conteúdos da Antropologia, a partir da experiência de nossas pesquisas. Nosso interesse é compreender o processo de ensino/aprendizagem da Antropologia, e, assim, os desafios das Ciências Sociais partindo da perspectiva do professor na educação Básica.

\section{A importância das Ciências Sociais para uma sociedade reflexiva}

O argumento central da importância das Ciências Sociais aponta para o seu papel na construção da identidade plural e democrática da sociedade moderna. No âmbito da discussão acadêmica em Ciências Sociais, com efeito, os princípios morais e os projetos civilizadores fundamentais da epistemologia ${ }^{4}$ euroamericana - tais como a emancipação humana da tradição e a felicidade individual - experimentaram historicamente considerável amadurecimento teórico. Este desenvolvimento da crítica social pode ser destacado no processo de elaboração do discurso sociológico, antropológico e politológico de progresso civilizacional, de ordem social, de crescimento econômico e de acúmulo da experiência coletiva de controle e de administração instrumental da Natureza e da Cultura. Este amplo projeto de tempo longo, que se estende pela Renascença, pelo Iluminismo e chega à contemporaneidade da nossa atual Modernidade Reflexiva (GIDDENS, 1991; 2002), expressa pela Sociedade de Risco (BECK, 2002) - implicou na produção coletiva de um conhecimento secular e empírico sobre o real social. Conhecimento este que pretende dissociar-se do mito e da especulação para constituir um saber científico legítimo especializado, autônomo e burocratizado.

As Ciências Sociais constituíram-se historicamente em conformidade com esse processo evolutivo de busca por uma representação verdadeira do real social que redundou na formulação de um Conhecimento Positivo - que distingue entre Ciência e não Ciência - e na demarcação entre saberes tradicionais, do senso comum, religiosos e científicos sobre a vida humana em seus aspectos sociais, culturais e biopsíquicos; distinguindo assim, dessa vez,

\footnotetext{
4 Para uma discussão mais detalhada sobre a fundamentação epistemológica na formação do professor-
} pesquisador, ver Soffner e Kirsch (2018). 
entre Conhecimento Metodologicamente Afiançado e pautado em Dados Objetivos, de um lado, e Artes, Filosofia, Humanidades, Letras, do outro (PIRES, 2010). As Ciências Sociais se estabelecem, portanto, no que se convencionou ser a segunda distinção epistemológica de construção do projeto moderno de Ciência, de modo que tem como espelho de aproximação as Ciências Naturais e como espelho de distanciamento a Filosofia e as Artes.

Nesse ínterim, a noção de dados objetivos passa a abarcar um repertório amplo de possibilidade analíticas, descritivas e de experimentação, tais como o laboratório, o arquivo e a pesquisa de campo. Ao passo que, em paralelo, a noção de metodologia científica nas Ciências Sociais se estabelece sob o primado de que a busca pela verdade deveria pautar-se em práticas impessoais, verificáveis e falsificáveis de formatação de assertivas a partir de registros axiologicamente neutros.

Nessa fase de desenvolvimento das Ciências Sociais - que remete aos trabalhos de Marx, Durkheim, Tarde, Spencer, Simmel, Weber, Frazer, Morgan e outros - a noção de descoberta científica, tão cara ao ideário positivista de progresso técnico e civilizatório, passa a cristalizar-se, no discurso das Ciências Sociais como: a) o exercício de revelar tabus, interditos, problemas sociais invisibilizados e silenciados no espaço público e não enquadrados como problema político; b) o esforço de impedir que arenas públicas e políticas de produção de conhecimento sobre o real social sejam extintas pelos interesses religiosos, econômicos e políticos; c) o compromisso com a missão emancipadora da produção científica em relação à tradição, ao senso comum e aos saberes mágicos, mitológicos e religiosos; d) e, por fim, o enquadramento teórico-metodológico do cotidiano e da história como laboratório humano, em que o senso comum e movimentos sociais atuam na produção das descobertas científicas.

Caber ressaltar, no processo supracitado de maturação histórica, acadêmica e institucional das Ciências Sociais, a sua imensa herança epistemológica e teóricometodológica de práticas discursivas renascentistas, iluministas e de contextos políticos revolucionários e modernizantes, como a Filosofia Política, a Filosofia da História, o Levantamento e a Reforma Social, e a Biologia (BOTTOMORE, 1971). Nesse diapasão, as Ciências Sociais acomodam imperativos axiológicos de controle positivo e prático do Meio Natural e Humano, presentes em vocabulários técnicos e conceituais de paradigmas da Física (Fluxo, Quantidade, Dinâmica, Mecânica, Entropia, Equilíbrio, Relações de Forças), da Biologia (Tecido, Órgão, Morfologia, Fisiologia, Função, Patologia, Doença, Evolução), da História e da Filosofia (Progresso e Evolução Social, Evento, Tempo e Espaço, Humanidade, 
Teologia e Teleologia, Sociedade Política e Sociedade Civil, Estado, Dialética), e da Matemática (Estatística, Geometria, Volume, Área, Saturação, Função).

Enquanto saber científico fortemente influenciado pelas revoluções burguesas ou modernizantes que fundam a modernidade urbano-industrial, racional-burocrática e o EstadoNação - tais como a Revolução Inglesa, a Revolução Industrial, a Reforma Protestante, a Revolução Francesa, a Revolução Americana, o Movimento Independentista e Republicano na América, a Revolução Russa, a Revolução Chinesa e demais movimentos que historicamente marcaram rupturas com modos tradicionais de vida - as Ciências Sociais paulatinamente desenvolvem um olhar analítico sobre a sociedade e a cultura, primeiramente em torno do Problema ou Questão Social e, ato contínuo, sobre outros aspectos problemáticos e desafiadores do real social e cultural, sintetizados, por exemplo, como a Questão Urbana, a Questão Política ou a Questão Ecológica. Destacam-se, na elaboração científica da Questão Social que dominou os debates em Ciências Sociais do século XIX, a teoria do materialismo histórico, de Marx; a teoria da racionalização do social, de Weber; e a teoria da solidariedade social, de Durkheim.

A esta altura tem-se consolidada a noção de Ciências Sociais como prática acadêmica e profissional, cujos modelos de explicação causal e de compreensão de tendências da Estrutura Social - a complexa rede de instituições e grupos em conexão social sistêmica - e da Estrutura Simbólica - a complexa rede de comunicação, de parentesco e de rituais públicos fazem jus à sua nominação híbrida greco-romana: o socius, de tradição latina, remete à classificação relacional da vida humana; o logos, de tradição grega, aponta para a classificação simbólica dos fatos sociais. As Ciências Sociais consolidaram-se, então, como o saber científico geral sobre a sociedade, apresentando gradualmente métodos e esquemas conceituais mais precisos em substituição de teorias gerais e sistemas explicativos finais e fechados de cunho conservantista.

O conservantismo era, então, a preocupação obsessiva com a perda da tradição, que a olhos vistos acontecia resultante dos irreversíveis processos de modernização. Estes processos que erigiam cidades, indústrias, fábricas, mercados, burocracias, ciências, e, em síntese, a pulsante vida atual em regime de capitalismo informacional globalizado que as Ciências Sociais se esforçam atualmente em explicar, compreender, historicizar, descrever e interpretar, fomentavam posturas morais e emocionais cada vez mais individualistas. Este modo de navegação social produzia novas culturas em conformidade com os vínculos socais efêmeros, pontuais, racionalizados, impessoalizados e institucionalizados do urbanismo que despontava como estilo de vida. 
As Ciências Sociais estariam, pois, ligadas à construção coletiva de uma massa crítica de consciência e de compreensão para a emancipação humana desde a problematização sistemática da experiência (objetiva) e da vivência (subjetiva) individual para além dos seus horizontes morais e emocionais, cognitivos e comportamentais, temporal e espacialmente limitados. Bauman (2015), por exemplo, nesse diapasão, conclui que as Ciências Sociais podem ser definidas como o exercício de de-construção teórica da realidade social, de modo a posicionar em bases diversas de compreensão e de explicação a tensa relação entre indivíduo, cultura e sociedade. E eis assim a importância das Ciências Sociais na Escola.

\section{A Sociologia enquanto espaço das Ciências Sociais na escola}

A Sociologia compreende o espaço formativo alcançado pelas Ciências Sociais na escola, através de sua obrigatoriedade no Ensino Médio, com a implementação da Lei 11.684/08 (BRASIL, 2008). A Lei de Diretrizes Bases da Educação evidencia a importância do ensino da Sociologia na escola, estabelecendo como uma das finalidades centrais do seu ensino a construção da cidadania do educando.

Tendo em vista que o conhecimento sociológico tem como atribuições básicas investigar, identificar, descrever, classificar e interpretar/explicar todos os fatos relacionados à vida social, logo permite instrumentalizar o aluno para que possa decodificar a complexidade da realidade social. Assim, seja na escola ou em qualquer outra instituição pedagógica, como as políticas públicas de educação e tudo o que configure um lugar por excelência do ensinare-aprender, é preciso compreender que existimos dentro de redes e teias de símbolos, de significados, de instituições sociais, de formas evidentes ou camufladas de poder, como nos alerta Brandão (2007, p. 14). O retorno da disciplina de Sociologia à Educação Básica representou uma luta por parte de Sociólogos de todo o Brasil. E mesmo o nome da disciplina sendo Sociologia, a mesma deve ser obrigatoriamente ministrada por um profissional com formação docente em Ciências Sociais, como está previsto nas Orientações Curriculares Nacionais (OCNs). A obrigatoriedade da disciplina de Sociologia nos currículos do Ensino Médio, espaço por excelência das ciências sociais que deve conjugar conhecimentos de Sociologia, Antropologia e Ciência Política - impele a Antropologia a construir um novo lócus para debate e a refletir sobre as questões referentes à Educação Básica. Agora, o ensino de conteúdos antes pensados apenas para o Ensino Superior deve também ser pensado para o 
Ensino Médio, apresentando desafios para os professores com essa formação, tanto no nível pedagógico quanto metodológico ${ }^{5}$.

É necessário destacar que aos 16 dias de fevereiro de 2017 foi sancionada no Diário Oficial da União a Lei 13.415, que altera as Leis 9.394 e 11.494:

\begin{abstract}
Altera as Leis $\mathrm{n}^{\circ}$ 9.394, de 20 de dezembro de 1996, que estabelece as diretrizes e bases da educação nacional, e 11.494, de 20 de junho 2007, que regulamenta o Fundo de Manutenção e Desenvolvimento da Educação Básica e de Valorização dos Profissionais da Educação, a Consolidação das Leis do Trabalho - CLT, aprovada pelo Decreto-Lei no 5.452, de 10 de maio de 1943, e o Decreto-Lei no 236, de 28 de fevereiro de 1967; revoga a Lei no 11.161 , de 5 de agosto de 2005; e institui a Política de Fomento à Implementação de Escolas de Ensino Médio em Tempo Integral (BRASIL, $2017 \mathrm{a}, \mathrm{s} / \mathrm{p})$.
\end{abstract}

Esta reforma na legislação transfere a obrigatoriedade do ensino de Educação Física, Arte, Sociologia e Filosofia no Currículo do Ensino Médio para a Base Nacional Curricular Comum:

$\S 1$ o A parte diversificada dos currículos de que trata o caput do art. 26, definida em cada sistema de ensino, deverá estar harmonizada à Base Nacional Comum Curricular e ser articulada a partir do contexto histórico, econômico, social, ambiental e cultural.

§ 20 A Base Nacional Comum Curricular referente ao ensino médio incluirá obrigatoriamente estudos e práticas de educação física, arte, sociologia e filosofia (BRASIL, 2017b, s/p).

A mudança na legislação anula a obrigatoriedade do ensino de Sociologia no Ensino Médio, sugerindo o estudo das Ciências Sociais, em suas perspectivas sociológicas, antropológicas e políticas pela Base Nacional Comum Curricular. Mas é preciso entender que o estabelecimento e o fortalecimento da Sociologia no Ensino Médio tendem a contribuir para a ampliação do contexto da simples profisssionalização e da formação técnica, na medida em que podem representar uma tomada de consciência de aspectos relevantes da ação dos sujeitos e da realidade em que estamos inseridos.

Acreditamos que a busca por uma alternativa ao ensino tradicional deve ser a tônica em todas as disciplinas na escola, mas principalmente na Sociologia, dado seu viés problematizador da realidade social e suas funções de "estranhamento" e "desnaturalização", conforme previstas nas Orientações Curriculares para o Ensino Médio (BRASIL, 2006).

\footnotetext{
${ }^{5}$ A discussão sobre a formação dos professores no Brasil, com referência às novas Diretrizes Curriculares Nacionais para a formação inicial e continuada dos professores da Educação Básica, foi aprofundada por Medeiros e Aguiar (2018)
} 
O ensino de Sociologia permite que a Antropologia e a Ciência Política, que embora não sejam disciplinas obrigatórias, possam fazer parte da formação e estejam presentes no processo de ensino-aprendizagem. Nesse contexto, é importante considerar o fato de a Antropologia fornecer elementos teórico-metodológicos para se pensar as sociedades atuais. A partir de noções como experiências culturais, rede de relações, papéis sociais e o processo de constituição das identidades sociais, pode-se compreender os contextos sociais, culturais, políticos e econômicos através dos constantes fluxos, dos hibridismos, do multiculturalismo, das novas identidades e sociabilidades contemporâneas, na maioria das vezes marcados por atitudes etnocêntricas e de diferenciações entre "nós" e os "outros".

O papel da Sociologia, e consequentemente da Antropologia, na escola, está atrelado a uma formação para a cidadania e vivência com as diversidades, contribuindo para o desenvolvimento de competências cognitivas e culturais, levando em consideração os conhecimentos prévios dos jovens estudantes ${ }^{6}$. Problemas como o reconhecimento da alteridade, e das diversas formas de exclusão e desigualdades sociais no Brasil e no mundo, podem ser abordados a partir de uma perspectiva socioantropológica.

O estudo da antropologia é também uma forma de educação na medida em que nos convida a ver no outro e em suas diferenças, muitas vezes, formas alternativas de sociabilidade ou de resolução de conflitos entre os homens. Quem sabe, assim, nos possibilitando maior abertura (visual, dialógica, intelectual, cognitiva e afetiva) para enfrentar os problemas da vida cotidiana. Nesse sentido, considerando os desafios vividos na educação, escolarizada ou não (ROCHA; TOSTA, 2009, p. 20).

Desse modo, a Antropologia pode contribuir com as discussões sobre essas temáticas, oferecendo referenciais para a formação de uma consciência cidadã, de acordo com as Orientações Curriculares para o Ensino Médio - Ciências Humanas e suas Tecnologias, no que se refere à contextualização sociocultural (BRASIL, 2006, p. 34).

\section{Antropologia na escola: como e por quê?}

Como se pode evidenciar, nos últimos anos a Antropologia tem expandido sua presença junto às mais diversas formações não universitárias, e a escola constitui um desses espaços formativos. Nesta perspectiva, tem se iniciado no Brasil um debate mais aprofundado em torno do ensino da Antropologia na Educação Básica, a partir de seus conteúdos na disciplina de Sociologia.

${ }^{6}$ Esta discussão sobre Educação e Diversidade é explorada por Campos, Grando e Passos (2015). 
A Antropologia, em seu diálogo com a Educação, ainda é considerado um debate pouco explorado, mesmo quando a História da Antropologia evidencia que importantes antropólogos se tornaram referência para o estudo de questões educacionais (GUSMÃO, 1997). Desde a criação da moderna Antropologia, houve e ainda há um grande e persistente distanciamento frente ao que tenha a ver com os processos e as estruturas intencionais e agenciadas de socialização pedagógica de crianças, adolescentes e jovens (BRANDÃO, 2007, p. 4).

Mas claro, como nos lembram os autores supracitados, é verdade que houve exceções, mesmo em apenas raras ocasiões, quando elas foram visíveis e causaram algum impacto maior, como foi o caso da escola norte-americana de cultura e personalidade. Essa tendência, que teve uma vida curta, mas fecunda, entre as décadas de 1940 e 1960, motivou antropólogos como Margareth Mead, Ralph Linton e Ruth Benedict, com interesses voltados para as relações culturais de socialização e seus efeitos na formação social de um determinado tipo de “personalidade" e de "cultura" (BRANDÃO, 2007, p. 4).

Mas é fato que são poucos os antropólogos que se dedicam ao estudo da temática da Educação. Apenas de maneira acidental a educação formal e a instituição escolar são alvo de seus interesses, até porque quase todas as etnografias foram realizadas junto a culturas indígenas, quase sempre alheias à escola e ao profissional da educação, ressalta Brandão (2007, p. 5). A educação passa a ser mais evidente nos estudos antropológicos quando se trata de temas relacionados a outros interesses, como por exemplo, a questão indígena ou quilombola.

Somente de alguns anos para cá, a partir das políticas educacionais voltadas para esses grupos, as questões sobre educação se fazem mais presentes, abrindo-se entre antropólogos e educadores um interesse convergente em torno dessa cara temática. Segundo Brandão (2009), durante muito tempo a Antropologia ignorou as formas nativas ou populares de educação de crianças e jovens. A educação que lhes era direcionada procurava civilizá-los, tornando-os uma figura meio híbrida e marginalizada, "nem ainda um índio e nem já um branco".

Mas, não é de se estranhar que a Antropologia que nasce da pesquisa de observação participante junto a comunidades tribais se interessasse muito mais pelos ritos de passagem ou "formatura", e pelo destino social do "formado", do que pelo trabalho escolar cotidiano de sua formação através da aprendizagem, escolar ou não, como bem afirma Brandão (2007, p. 5). "Em parte, isso se deve ao fato de que uma primeira antropologia - e a de hoje em dia também, em boa medida - foi quase insensível ao mundo de crianças e de adolescentes, a não ser em momentos de estudos de ritos de passagem" (BRANDÃO, 2009, p. 13). 
No Brasil, particularmente, ainda no conjunto de fatores que dificultaram o diálogo entre Antropologia e Educação, tem-se ainda a formação do educador, que passava por diferentes disciplinas centrais ou afluentes da Pedagogia, da História da Educação, ao lado de algumas esparsas Psicologias centradas na questão da aprendizagem, complementada por uma formação precária em Sociologia da Educação para completar o quadro. E, nesse contexto, não podemos esquecer que, bem antes de ter sido descoberto pela academia e pela Pedagogia das universidades, e até mesmo pela própria Antropologia, esse diálogo foi fortemente enfatizado pelos movimentos de Cultura Popular da década de 1960, a partir da relação entre Cultura e Educação. Os trabalhos de Paulo Freire representam o lócus desse debate e a memória dessa trajetória (BRANDÃO, 2009, p. 13-14).

Mas, antes de pretender se pensar na Educação como objeto de estudo por parte dos antropólogos, as reflexões que nos interessam dizem respeito ao ensino de Antropologia e suas metodologias, particularmente na educação básica. São escassos os debates sobre metodologias de ensino e sobre estratégias de aproximação do saber antropológico em sala de aula. Assim, um debate mais estreito entre Antropologia e a Educação, por exemplo, parece cada vez mais necessário. Para isso, é preciso que a Antropologia repense as formas de operacionalizar seu saber, para além daquele voltado à pesquisa em si, mas que se amplie para além dos muros da academia.

Partimos do pressuposto de que a Antropologia, dentro da disciplina de Sociologia, pode ajudar alunos e professores da Educação Básica a conhecer, relativizar e pensar criticamente a diversidade e a desigualdade que conforma a realidade brasileira, desmistificando noções já naturalizadas e/ou essencializadas. À Antropologia cabe a investigação sobre a especificidade do comportamento, da organização, dos valores, sentimentos e crenças das sociedades humanas, enfim, seu estilo de vida e cosmovisão.

Ancorados em metodologia própria, os antropólogos estão habilitados a oferecer interpretações de práticas culturais e de representações simbólicas específicas dos diferentes grupos sociais, proporcionando um olhar de alcance profundo sobre a vida em sociedade. Com esta finalidade, a coleta de dados empíricos, etnográficos, por meio do trabalho de campo, dos levantamentos de histórias de vida, depoimentos e entrevistas em profundidade, pesquisa documental de fontes primárias, secundárias e teóricas, permite interpretações de realidades que podem nortear antropologicamente as possibilidades de atuação de instituições, envolvendo os diferentes grupos sociais, culturais e políticos.

$\mathrm{Na}$ atual conjuntura, além de viver de maneira densa e dramática a sua própria experiência de aprendiz, o antropólogo é colocado à prova por seus próprios "objetos" de 
estudos. Nesse sentido, tanto do ponto de vista teórico quanto do metodológico, o antropólogo se vê na obrigação de repensar, reavaliar, reinterpretar seus próprios modelos, teorias e métodos, além de aprender com a diferença do "outro" (ROCHA; TOSTA, 2009, p. 18).

Assim, da mesma forma que o professor de Sociologia precisa adequar sua abordagem no que diz respeito a temas relacionados à Antropologia, permitindo que estes possam ser trabalhados dentro das aulas de Sociologia - uma vez que é sob o jugo desta disciplina que adentramos na Educação Básica - o aluno precisa ter a oportunidade de exercitar os conhecimentos adquiridos em sala de aula, de modo que experimente na prática esse saber, descobrindo por si só o fazer científico.

Cabe à Antropologia também refletir acerca de suas relações com a Educação, dado que seus conceitos e temas adentrarão a Educação Básica, ganhando uma nova forma de divulgação fora dos muros acadêmicos. Tal movimento traz diversos desafios, que devem ser assumidos pelos antropólogos, tanto em relação à formação de licenciados em Ciências Sociais, desenvolvendo metodologias de ensino que deem conta da transposição didática dos conteúdos para tal nível de ensino, como também de certificar-se se e como estes conteúdos estão sendo assimilados pelos alunos, refletindo ainda sobre formas de se contribuir para este fim.

A Antropologia em sua relação com a educação se pretende um instrumento capaz de somar para um ensino mais humanista, melhor e mais eficiente no cenário das instituições formadoras no Brasil, sejam elas públicas ou privadas, e em todas as modalidades de educação. Como nos mostra Rocha e Tosta (2009, p. 17):

A antropologia é uma forma de educação, bem como a educação só é possível como prática antropológica. Eis o pressuposto a partir do qual apresentamos, aos profissionais da educação (professores de todas as modalidades de ensino, especialmente os formadores de professores e os agentes sociais que trabalham com projetos socioeducativos) e aos estudantes das licenciaturas e de outras áreas em geral, a maneira como pensamos a antropologia. A antropologia não é somente uma disciplina acadêmica capaz de fornecer uma explicação sobre as representações da alteridade e/ou as práticas do "outro", mas uma forma de produzir um sentido humanista às nossas experiências no mundo da vida cotidiana.

Assim, é importante pensarmos na operacionalização e viabilização desse objetivo do ensino da Antropologia, de produzir um sentido humanista para as experiências cotidianas do aluno. No nível da Educação Básica, ainda levar o aluno a exercitar os conhecimentos adquiridos em sua sala de aula para inteirá-lo nas discussões socioculturais de seu tempo. Porém, o que se observa no cotidiano de nossas escolas e na universidade são esforços muito 
pequenos no que diz respeito ao desenvolvimento de estratégias para a aplicação dessas concepções em sala de aula.

\section{Antropologia na escola: o que pensam os professores}

Uma pesquisa realizada a partir do Programa de Bolsas de Iniciação Científica PIBIC, no ano de 2017, com três professores de Sociologia de três escolas públicas de Mossoró/RN - Escola Estadual Professora Maria Stella Pinheiro Costa, Escola Estadual Moreira Dias e o Centro de Educação Integrada Professor Eliseu Viana, verificou algumas das principais dificuldades na transposição dos conteúdos não apenas da Antropologia, mas das três áreas das Ciências Sociais neste nível de ensino. A pesquisa se deu por meio de entrevistas, além de observação participante nas aulas de Sociologia, especialmente nas que foram ministrados conteúdos de Antropologia.

Os três professores entrevistados, entre os quais temos um homem e duas mulheres, têm formação em Ciências Sociais pela Universidade do Estado do Rio Grande do Norte UERN. Cada professor e sua respectiva escola estão vinculados ao Programa Institucional de Bolsa de Iniciação à Docência-PIBID, do curso Ciências Sociais da UERN. A escolha das escolas vinculadas ao PIBID possibilitou uma maior inserção no campo de pesquisa e uma melhor interação com os professores e suas respectivas turmas.

Verificou-se entre os professores uma concordância de que não existe a separação das três áreas do conhecimento em sala de aula, porém eles admitiram que o foco maior está na área da Sociologia. O livro didático mais utilizado é Sociologia para Ensino Médio do Nelson Tomazi, seguido pelo livro Sociologia em Movimento, mas todos afirmaram usar também outros materiais direcionados para o ensino médio. Os professores também afirmaram fazer uso de metodologias diversificadas em suas aulas, como mostra de filmes, documentários e músicas, bem como a leitura compartilhada e o roteiro de estudo.

Entre os temas mais abordados nos conteúdos de Antropologia, o conceito de cultura se destaca, e é o mais mencionado, derivando deste discussões voltadas para o etnocentrismo e relativismo cultural, diversidade cultural, identidade e diferença. "Apesar das especificidades de cada turma e das afinidades dos alunos com cada área, a Antropologia e seus conteúdos se mostram na maioria das vezes mais atraente, no sentido de trabalhar questões que tocam a vida deles, sobretudo no que se refere à questão de gênero, sexualidade, racismo e preconceito", afirmou uma das professoras entrevistadas. E é nessa perspectiva que a observação participante tem, entre as metodologias utilizadas como estratégias de 
aproximação do saber antropológico em sala de aula, maior destaque, visto que possibilita essa aproximação com o cotidiano dos alunos.

A maior dificuldade apontada pelos professores no ensino de Antropologia dentro da disciplina de Sociologia é o tempo, ou seja, a carga horária. "Uma hora aula semanal para se repassar o conteúdo não de uma disciplina, mas de três", como aponta outra professora. Esse curto tempo limita não apenas as discussões dos conteúdos, mas as próprias metodologias a serem utilizadas, como a mostra de filmes, por exemplo.

Apesar das dificuldades, é evidente as contribuições do ensino da Antropologia na educação básica, no sentido que ajuda os alunos a refletirem sobre o seu próprio cotidiano. Deixou claro que o ensino da Antropologia, através da disciplina de Sociologia, pode ajudar alunos e professores da Educação Básica a conhecer, relativizar e pensar criticamente a diversidade e a desigualdade que conforma a realidade brasileira, desmistificando noções já naturalizadas.

Após refletir sobre a visão dos professores, o direcionamento passa a focar na perspectiva dos próprios alunos, com o objetivo de investigar como os conteúdos de Antropologia estão sendo assimilados pelos mesmos na Educação Básica nas escolas públicas da cidade de Mossoró/RN.

\section{Considerações finais}

A Antropologia, ao refletir e estreitar suas relações com a Educação, através da Educação Básica, ganha, além de uma nova forma de divulgação fora dos muros acadêmicos, a oportunidade de transformar o olhar sobre o outro junto a esse público tão específico. Tal experiência traz obviamente diversos desafios, os quais devem ser assumidos pelos antropólogos, que devem começar a pensar e desenvolver práticas metodológicas que permitam e facilitem o acesso a seus conhecimentos para além dos muros da academia.

Isso reflete diretamente na formação dos licenciados em Ciências Sociais, que responsáveis pelo ensino de Sociologia na Educação Básica, devem preocupar-se também com metodologias que deem conta da transposição didática dos conteúdos para esse nível de ensino. Mais do que nunca se faz necessário pensarmos na operacionalização e viabilização dos conhecimentos das Ciências Sociais na Educação Básica. No tocante à Antropologia, muito mais que conhecimentos, ao possibilitar uma nova forma de olhar o outro, de exercitar a empatia, de refletir valores e a descoberta da identidade, oferecendo sentido humanista às 
experiências cotidianas, seus saberes atestam sua importância e relevância nessa etapa da formação.

É nessa perspectiva que defendemos que o professor de Sociologia precisa investir na abordagem dos temas da Antropologia em sala de aula. Uma vez que é nesta disciplina que as ciências sociais adentram na Educação Básica, a Sociologia carrega a responsabilidade e o desafio de pensar a operacionalização dos seus conhecimentos. As estratégias de ensino precisam atender às expectativas diversas dos alunos em relação ao professor e ao conteúdo de Sociologia. Não é o caso agora de formarmos cientistas sociais na Educação Básica, mas de cumprir o mínimo daquilo que a LDB - Lei de Diretrizes e Bases da Educação, Lei 9.394 de 1996 - determina (BRASIL, 1996).

Trata-se inicialmente de oportunizar o estabelecimento de um diálogo entre os conteúdos escolares e a realidade na qual os alunos estão inseridos. Poderia ser simples assim. Mas os inúmeros problemas impostos pelo nosso sistema de ensino dificultam a tarefa que por si só já parece tão árdua. E consequentemente, é na própria formação em Ciências Sociais que tudo começa. Um outro debate sobre o contexto atual das licenciaturas no país e a então crise política brasileira teria que ser aprofundado para compreendermos os reais problemas da formação de professores no Brasil, considerando a legislação relativa a essa formação, ou seja, a atual LDB - e as questões referentes às características dos cursos formadores de professores, currículos etc.

Por enquanto, nos limitamos a pensar nas Ciências Sociais como uma área de ensino ainda não tão forte na tradição do exercício da docência na Educação Básica. Por isso a aposta se dará no seu profissional, no sentido de que este construa caminhos de abertura da sua formação na Educação Básica, ampliando a transversalidade do conhecimento das Ciências Sociais, tão essencial para a educação. E que nesta perspectiva a Antropologia tenha espaço para poder dar sua contribuição. Isso nos motiva a reafirmar o princípio segundo o qual a Antropologia deve ser pensada muito mais que uma área de conhecimento, mas como uma forma de educação, ou como uma das formas em que a educação deve ser vivida, ou seja, como uma prática antropológica, uma troca de conhecimentos pautada no exercício da empatia.

\section{REFERÊNCIAS}

BAUMAN, Z. Para que serve a Sociologia? Diálogos com Michael Hviid Jacobsen e Keith Tester. Rio de Janeiro, RJ: Zahar, 2015. 
BECK, U. La sociedade del riesgo. Hacia uma nueva modernidade. Barcelona, Buenos Aires: Paidós, 2002.

BOTTOMORE, T. B. Introdução à sociologia. Rio de Janeiro, RJ: Zahar Editores, 1971.

BRANDÃO, C. R. Algumas palavras sobre a cultura e a educação In: ROCHA, G.; TOSTA, S. P. Antropologia \& educação. Belo Horizonte, MG: Autêntica Editora, 2009. (Coleção Temas \& Educação; 10)

BRANDÃO, C. R. Sobre teias e tramas de aprender e ensinar: anotações a respeito de uma antropologia da educação. Revista Inter Ação, Goiânia (GO), v. 26, n. 1, p. 9-30, 2007. DOI: doi.org/10.5216/ia.v26i1.1552

BRASIL. Lei n. 9.394, de 20 de dezembro de 1996. Estabelece as Diretrizes e Bases da Educação Nacional. Brasília, DF, 23 dez. 1996. Disponível em:

http://www.planalto.gov.br/ccivil_03/leis/19394.htm. Acesso em: 10 set. 2020.

BRASIL. Ministério da Educação. Secretaria da Educação Básica. Orientações Curriculares para o Ensino Médio. Brasília, DF: MEC, SEF, 2006. v. 3.

BRASIL. Lei n. 11.684, de 2 de junho de 2008. Altera o art. 36 da Lei no 9.394, de 20 de dezembro de 1996, que estabelece as diretrizes e bases da educação nacional, para incluir a Filosofia e a Sociologia como disciplinas obrigatórias nos currículos do ensino médio. Brasília, DF, 03 jun. 2008. Disponível em: http://www.planalto.gov.br/ccivil_03/_Ato20072010/2008/Lei/L11684.htm. Acesso em: 10 set. 2020.

BRASIL. Lei n. 13.415, de 16 de fevereiro de 2017. Altera as Diretrizes e Bases da Educação Nacional. Brasília, DF, 17 fev. 2017a. Disponível em:

http://www.planalto.gov.br/ccivil_03/_ato2015-2018/2017/lei/113415.htm. Acesso em: 10 set. 2020 .

BRASIL. Ministério da Educação. Base Nacional Curricular Comum. Brasília, DF: MEC, $2017 b$.

CAMPOS, N. S.; GRANDO, B. S.; PASSOS, L. A. Educação e diversidade: as experiências exitosas que reconhecem os saberes e fazeres da cultura na escola. Revista Ibero-Americana de Estudos em Educação, Araraquara, v. 10, n. 4, p. 1261-1277, out./dez. 2015. DOI: doi.org/10.21723/riaee.v10i4.6332

GIDDENS, A. As consequências da modernidade. São Paulo, SP: Editora Unesp, 1991.

GIDDENS, A. Modernidade e identidade. Rio de Janeiro, RJ: Zahar, 2002.

GUSMÃO, N. M. M. Antropologia e educação: origens de um diálogo. Cadernos CEDES, Campinas (SP), v. 18, n. 43, dez. 1997. 
KIRSCH, D. B.; SOFFNER, R. K. Formação do professor-pesquisador: a importância da fundamentação epistemológica. Revista Ibero-Americana de Estudos em Educação, Araraquara, v. 13, n. esp. 3, p. p. 2087-2099, dez. 2018. DOI:

doi.org/10.21723/riaee.unesp.v13.iesp3.dez.2018.10892

MEDEIROS, E. A.; AGUIAR, A. L. O. Formação inicial de professores da educação básica em licenciaturas de universidades públicas do Rio Grande do Norte: estudo de currículos e suas matrizes curriculares. Revista Ibero-Americana de Estudos em Educação, Araraquara, v.13, n. 3, p. 1028-1049, jul./set. 2018. DOI: doi.org/10.21723/riaee.v13.n3.2018.10975

PIRES, Á. P. Sobre algumas questões epistemológicas de uma metodologia geral para as ciências sociais. In: POUPART, J. et al. A Pesquisa qualitativa. Enfoques epistemológicos e metodológicos. Rio de Janeiro, RJ: Editora Vozes, 2010.

ROCHA, G.; TOSTA, S. P. Introdução. In: ROCHA, G.; TOSTA, S. P. Antropologia \& educação. Belo Horizonte, MG: Autêntica Editora, 2009. (Coleção Temas \& Educação; 10)

\section{Como referenciar este artigo}

SILVA, E. A.; BARBOSA, R. B.; CUNHA, L. A. As ciências sociais e o desafio da antropologia na prática docente na educação básica. Revista Ibero-Americana de Estudos em Educação, Araraquara, v. 16, n. esp. 3, p. 1493-1508, jun. 2021. e-ISSN: 1982-5587. DOI: https://doi.org/10.21723/riaee.v16iesp.3.15294

Submissão em: 05/02/2021

Revisões requeridas em: 30/03/2021

Aprovado em: $12 / 05 / 2021$

Publicado em: 01/06/2021 